\title{
Critical bands and mixed-frequency scaling: Sequential dependencies, equal-loudness contours, and power function exponents
}

\author{
LAWRENCE M. WARD \\ University of British Columbia, Vancouver, British Columbia, Canada
}

\begin{abstract}
Stimuli of random intensities and various but predictable frequencies were presented for repeated magnitude estimations on the same scale (mixed-frequency scaling). The frequencies for a particular judgment session were selected so that they lay either inside each other's critical bands or outside them. Contrastive dependencies of current magnitude estimation responses on previous stimuli of a different frequency were significantly affected by whether the two frequencies were inside or outside each other's critical bands, while assimilative dependencies were not. This reinforces the idea that such dependencies are sensory in nature and arise from a different mechanism than do the assimilative dependencies. Mixed-frequency scaling of loudness also gives rise to cross-frequency matching functions from which equal-loudness contours can be calculated. These contours calculated from the present judgments are similar to those produced from other methods, even when they are extrapolated to untested intensities. Power function exponents for loudness scaled in this way are larger for lower frequencies, as has been found in previous studies, and are consistent with the flattening of the calculated equal-loudness contours for low frequencies as intensity increases.
\end{abstract}

Direct scaling methods in psychophysics have a venerable history, which in many ways parallels that of the study of loudness. In fact, it was in the service of the definition and measurement of loudness that S. S. Stevens (1956) undertook the first of many applications of the method of magnitude estimation that he systematized and popularized (see S. S. Stevens, 1975). Magnitude estimation can also be used to generate sensible equalloudness contours (Schneider, Wright, Edelheit, Hock, \& Humphrey, 1972), and it is one of the standard methods of judgment used in mixed-modality scaling (J. C. Stevens \& Marks, 1980; Ward, 1982), in which stimuli of random intensity but selected alternatingly from one or the other of two modalities are presented for judgment on the same scale. Cross-modality matching functions can be generated easily and efficiently using this method. The present paper describes an extension of mixed-modality scaling in which the two modalities are replaced by two different frequencies of sound, hence "mixed-frequency" scaling.

As useful as direct scaling methods are, however, they have proved to be subject to many "biases" of judgment. For many investigators (e.g., Poulton, Edwards, \& Fowler, 1980; S. S. Stevens, 1975), these biases are simply nuisances to be eliminated. However, for others (e.g., Luce, Baird, Green, \& Smith, 1980; Ward, 1979) they

This research was supported by a grant from the Natural Sciences and Engineering Research Council of Canada. I thank Odeis Geiger for help with running subjects and analyzing data. Address reprint requests to Lawrence M. Ward, Department of Psychology, University of British Columbia, 2136 West Mall, Vancouver, BC, V6T 1Y7, Canada. reveal fundamental properties of the processes by means of which the magnitudes of psychological experiences arise and are evaluated. For this reason, tests of models of those processes are important. Such a test is described in the present paper.

One of the most ubiquitous biases of direct scaling judgments, including magnitude estimations, is the dependency of the current judgment on previous stimuli and responses. In numerous studies, multiple regression analyses of the sequence of stimuli and responses have revealed negative regression coefficients for previous stimuli and positive ones for previous responses. The coefficients have generally been interpreted as indicating a contrast of the current response with previous stimuli and assimilation to previous responses. I have suggested (e.g., Ward, 1979, 1982) that the two effects arise from different mechanisms: assimilation to previous responses from a perceptual (categorization) process, and contrast to previous stimuli from a sensory process. This idea has been confirmed by the fact that when successive stimuli to be judged are selected from different modalities, as in mixedmodality scaling, contrast of the current response with previous stimuli is usually present only for previous stimuli from the same modality as that of the current stimulus, while assimilation to previous responses occurs regardless of the stimulus modality to which the response was made (Ward, 1982, 1985, 1986).

The present study implements a more subtle test of this idea. Stimulus contrast could arise from the interactions of internal, excitatory-center-inhibitory-surround representations of successive sensory stimuli (Ward, 1979). The absence of stimulus contrast across modalities implies 
that the relevant internal representations are sensory in nature and perhaps localizable within particular sensory processing areas. But even within a particular sensory processing area, such as primary or secondary sensory cortex, internal representations could vary in their degrees of interaction-in proportion to their distances from each other or their strengths of connectivity, for example.

In audition, the concept of a critical band of frequency (Fletcher, 1940; Hawkins \& Stevens, 1950; Scharf, 1959; Zwicker, Flottorp, \& Stevens, 1957) captures in a powerful way this idea of variation in the amount of interaction of sensory stimuli within the same modality. For example, sounds inside each other's critical bands mask each other much more strongly than they mask or are masked by sounds outside each other's critical bands. Also, loudness summation of different components of complex sounds occurs only for components outside of each other's critical bands, suggesting that separate representations of the various components exist only for components separated by at least 0.5 critical bandwidth. These and other results are consistent with a view of the auditory system as a bank of (overlapping) parallel bandpass filters (Fletcher, 1940).

The width of the critical band (CB, estimated either from masking or from loudness summation effects) varies with center frequency $(f)$ approximately according to

$$
\mathrm{CB}=0.002 f^{1.5}+100
$$

(Zwislocki, 1965). This curve is closely related to the patterns of vibration of the basilar membrane for the various frequencies. As is well known, the tonotopic mapping of frequency on the basilar membrane is repeated in the auditory nerve and in higher auditory centers, including the sensory cortex (see Coren \& Ward, 1989), although the neural representation of the lower frequencies is somewhat compressed relative to that on the basilar membrane. Thus, critical bands could be interpreted as reflecting neural regions, inside which representations of tones interact more strongly than they do outside those regions. If contrastive sequential dependencies arise from interactions of sensory representations of stimuli, as I have argued, then they may be greater for tones whose frequencies are inside each other's critical bands.

In the present study, assimilative and contrastive sequential dependencies were studied as a function of whether previous stimuli and responses to them were to tones of the same frequency or different frequencies and, if different, whether they were inside or outside each other's critical bands. The fuzzy judgment theory makes different predictions about what the effect of this manipulation will be on dependencies of the current response on previous stimuli and responses (Ward, 1979, 1982). Briefly, the theory proposes that for each stimulus presented to a subject in a judgment task, an internal representation is formed that is based on the activity of the sensory system that has transduced the stimulus. The internal representation is assumed to be a fuzzy subset
(Zadeh, 1965) of the set of possible sensation levels, and to have an excitatory-center-inhibitory-surround organization that results in mutual repulsion (contrast) of internal representations on current and previous trials (cf. Levine \& Grossberg, 1976). The internal representation (after repulsion) is then cross-correlated with each of the prototypes (also fuzzy subsets) of categories stored in long-term memory and rank ordered with respect to their central tendencies. This (perceptual) process often gives rise to more than one candidate category (satisfactory match). The resulting uncertainty is resolved by a heuristic process that chooses the category nearest to that used previously. This causes assimilation of the current category to the previous category, and this is passed on to the response stage by the mapping of the stimulus category chosen to an equivalent category on the response continuum, followed by the choice of a response whose magnitude sufficiently matches the prototype of that response category.

The prediction of the fuzzy judgment theory is that assimilative dependencies on previous responses should be relatively unaffected by the nature of the stimuli to which the responses were made, since these dependencies are presumed to arise from categorization processes that are relatively independent of the nature of the sensory representations they categorize. However, contrastive dependencies on previous stimuli should be affected by how strongly the sensory representations of previous and present stimuli interact. Since representations of tones of frequencies inside each other's critical bands would be expected to interact more strongly than those of tones of frequencies outside each other's critical bands, contrastive dependencies should be greater for the former than for the latter.

An earlier study by Luce and Green (1978) gave results that lend credibility to this prediction. Luce and Green presented stimuli at random intensities and with frequencies chosen randomly from 1000 or $4000 \mathrm{~Hz}$ (outside each other's critical bands) for magnitude estimations of loudness. The subjects were encouraged (by feedback) to be consistent and to try to achieve a power function exponent of 0.33 for the psychophysical function. Although there was some reduction in the correlation between successive responses when they were made to stimuli of different frequencies, the correlation depended on the separation between successive stimulus intensities in the same way, regardless of the sameness or difference of the frequencies of successive stimuli. Some of the observers also showed less dependence of the coefficient of variation of the ratio of successive responses on the separation between successive intensities when the frequencies were different than they did when the frequencies were the same. Both of these results support the idea that sequential dependencies may vary with the separation of frequencies of successive stimuli. However, Luce and Green did not attempt to measure these effects, nor did they consider contrastive stimulus dependencies. Also, their situation differed from the present one in many ways; 
in particular, they did not use a wide range of different frequencies, and they did not explicitly manipulate whether the frequencies used in a given run were inside or outside each other's critical bands.

\section{Equal-Loudness Contours}

The generation of equal-loudness contours also has a venerable history. However, study of even a few of the most cited papers will reveal great diversity in both method and results. Kingsbury (1927) presented pure tones monaurally through a high-impedance earphone and used the classical method of loudness balance (direct loudness matching of tones of different frequencies) and a standard of $700 \mathrm{~Hz}$ to obtain the contours. Fletcher and Munson (1933) presented tones binaurally through earphones and used the loudness balance method but corrected the sound intensities presented in the phones to reflect freefield intensities. Robinson and Dadson (1956) again used loudness balancing but presented the tones in free-field conditions. Ross (1967) paid much greater attention to the specification of the stimuli than previous investigators had. He measured the tones' intensities a few millimeters from the eardrum and controlled their distortion very carefully at all frequencies, while presenting tones through a miniature speaker attached to a custom-molded ear insert and asking subjects to directly match loudnesses. He also paid attention to differences in the contours across individuals.

Schneider et al. (1972) obtained magnitude estimations of tones of random intensity and frequency and then constructed equal-loudness contours from the psychophysical functions obtained for each frequency. In a later paper, Schneider and Bissett (1987) used yet another method, comparison of loudness intervals across frequencies, to generate equal-loudness contours. Finally, Molino (1973) investigated the effects of standards of different frequencies on both equal-loudness contours and the properties of the loudness matches on which they were based.

Across all of these studies and others not mentioned, there are fairly dramatic differences in the steepness, separation, and overall shapes of the contours across frequencies at various intensity levels. For example, at nearthreshold intensities, there is general agreement on a very steep slope of the contour below $1000 \mathrm{~Hz}$, although the steepness varies considerably across studies. However, the shape of the contour above $1000 \mathrm{~Hz}$ differs dramatically, depending on whether free-field or earphone presentation is used, presumably because of the various amplifications caused by the pinna and head in the free field. At higher intensities, the contours below $1000 \mathrm{~Hz}$ flatten out considerably, but by an amount that varies over a range of $40 \mathrm{~dB}$ or so across the studies mentioned above. Finally, the separation of the contours also depends on several factors, and especially on the standard frequency (Molino, 1973). Thus, although there does exist an ISO standard set of equal-loudness contours, based on a 1000 $\mathrm{Hz}$ standard, this standard is not usually obtained in actual laboratory investigations. As Kohfeld, Santee, and
Wallace (1981) suggested, it is necessary to produce contours specific to each proposed use of them, matched for the characteristics (e.g., earphone or free-field presentation, loudness balance or direct scaling method) in force in that situation. In particular, there has been to my knowledge only one study in which direct scaling was used to generate equal-loudness contours, that of Schneider et al. (1972). Thus, there exists a need to study further equal-loudness contours produced in this way. In the present study, cross-frequency loudness matching functions are obtained for a wide range of frequencies and intensities and are used to calculate equal-loudness contours that are compared both with those of Schneider et al. (1972) and with those produced by the classical method of direct loudness matching.

\section{Variation of Loudness Exponent with Frequency}

S. S. Stevens (1966) suggested that the flattening of equal-loudness contours at frequencies lower than about $400 \mathrm{~Hz}$ as intensity of the standard increased arises from larger power function exponents for loudness for tones of those lower frequencies, associated with elevated thresholds for tones of those frequencies and thus with the phenomenon of recruitment. Subsequently, larger power function exponents for psychophysical functions for low-frequency tones were found using direct scaling methods (Hellman \& Zwislocki, 1968; Schneider et al., 1972). Marks (1974) suggested that the exponent of the power function describing the psychophysical function for loudness $(n)$ is given by

$$
\begin{aligned}
& f \leq 400: n=2[0.33+0.0009(400-f)] \\
& f>400: n=2[0.33],
\end{aligned}
$$

where $f$ is the frequency of the pure tone whose loudness is judged. Note that above $400 \mathrm{~Hz}$ the exponent is simply $2 \times 0.33=0.66$, as asserted by S. S. Stevens (1975). Since psychophysical functions for a wide range of frequency pairs, compared both inside and outside each other's critical bands, were available in the present study, the dependence of the power function exponent on frequency was assessed again and compared with that observed in the earlier studies and with the prediction of Equation 2.

\section{METHOD}

\section{Subjects}

Four men and 4 women with no known hearing defects participated for pay. All of the subjects could easily hear all of the stimulus intensities at each frequency.

\section{Apparatus and Stimuli}

Pure tones were generated by a custom-built sound generator, in which frequency and intensity could be selected digitally by a computer for each judgment. Digital-to-analog converters within the sound generator programmed the selected frequency and intensity from standard sine wave generators and attenuators. The sounds were $1 \mathrm{sec}$ in duration and had rise and fall times of $2.5 \mathrm{msec}$. 
Pure tone frequencies of $65,100,200,250,1000,1100,9000$, and $10000 \mathrm{~Hz}$ were used. Eight frequency-pair conditions were created: In four, the two frequencies were inside each other's critical bands (separated by less than 0.5 bandwidth), whereas in the other four, the frequencies were widely separated and outside each other's critical bands. The four inside pairs (approximate critical bands in parentheses-see Equation 1 or Zwicker et al., 1957) were: $65 / 100(90), 200 / 250(100), 1000 / 1100(200)$, $9000 / 10000(2500)$. The four outside pairs were: $100 / 1000,200 / 1000,200 / 9000$, $1000 / 9000$.

Sound-pressure amplitudes for the various frequencies were measured at the approximate location of the eardrum with a precision sound-level meter (General Radio) and a custom-built artificial ear that functioned like a coupler. The (diotic) amplitudes of the sounds at each frequency that were presented to subjects for judgment were as follows: for 65,100 , and $1000 \mathrm{~Hz}$ (in the $100 / 1000$ condition only), sounds ranged from 58 to $103 \mathrm{~dB}$ in 5-dB steps; for 200 , 250,1000 (all other conditions), 1100,9000 , and $10000 \mathrm{~Hz}$, sounds ranged from 40 to $94 \mathrm{~dB}$ in $6-\mathrm{dB}$ steps.

A PDP-11/34A computer system controlled the presentation of the stimuli and recorded subjects' responses, which were entered on a dimly illuminated keyboard. Subjects sat in a dark Model 250A IAC sound-attenuation chamber while making their judgments. Sounds were presented diotically through Sharpe Pro HA 660 headphones. The headphones have large air cushions surrounding the speakers, and subjects were encouraged to adjust them so as to achieve a good seal between the cushion and the head, both to exclude external sounds such as those generated by the subjects' movements, and to minimize low-frequency leakage.

\section{Procedure}

Subjects made successive magnitude estimations of pure tones of one of two frequencies alternating strictly and of intensities (pseudo)randomly selected from the 10 intensities available at each frequency. The subjects were given instructions similar to those of Ward (1982), which were a modification of those of J. C. Stevens and Marks (1980). These included instructions to give numbers that appeared to match the loudness of each stimulus and to use " the same scale" of loudness for each judgment, in the sense that if tones of different frequencies seemed to have the same loudness they should be given the same number. An admonition not to worry about consistency with previous judgments was also given. A mediumintensity stimulus was presented at the start of each run and designated " 100 ," to provide a suggested modulus for the judgments. The frequency of the stimulus that demonstrated the modulus varied across subjects; sometimes it was the lower and sometimes the higher of the two frequencies being judged. Also, subjects' responses were restricted to the integers from 1 to 32,767 for reasons of (computer) convenience; this restriction has not affected results in previous, similar experiments (see Ward, 1982, 1985, 1986).

Each subject made two 300-trial runs in each of the eight conditions, for a total of 4,800 trials per subject. This resulted in about 30 judgments per intensity per frequency in each condition. Each subject ran the eight conditions in a different (counterbalanced) order.

\section{RESULTS AND DISCUSSION}

\section{Sequential Dependencies}

A useful summary of the magnitudes of sequential dependencies is the estimates of $\tau, \alpha_{i}$, and $\beta_{k}$ in the following linear regression equation:

$$
\begin{aligned}
\log R_{n}= & \tau \log I_{n}+\Sigma \alpha_{i} \log I_{n-i} \\
& +\Sigma \beta_{k} \log R_{n-k}+\delta+\epsilon,
\end{aligned}
$$

where $R_{n}$ is the response on trial $n$, and $I_{n}$ is the stimulus intensity on trial $\boldsymbol{n}$ (see Jesteadt, Luce, \& Green, 1977; Ward, 1979). For the present data, these regression coefficients were estimated for the data of individual subjects by hierarchical linear regression in which the independent variables were entered into the regression equation in the order of the most "recent" (closest to $R_{n}$ ), next most recent, and so forth (e.g., $I_{n}$ first, $R_{n-1}$ next, then $I_{n-1}$, etc.). For the coefficients reported here, $M=4$ and $N=4$, since coefficients for higher lags are seldom reliable. Tables 1 and 2 summarize the results of these analyses. The values in the tables are averages over the 8 subjects for each condition. Because of difficulty in interpreting the reliability of individual subjects' coefficients, the conclusions are based on $t$ tests on the average coefficients and on the average increase in $R^{2}$ associated with various previous stimuli or responses. Statistical tests of $R^{2}$ increases are problematic, because $R^{2}$ increases depend on the order of entry into the regression equation of the independent variables-in the present case, the hierarchical regression model described above. The regression coefficients do not vary in this way as long as all of the independent variables are present, but by themselves they do not give a complete picture of the size of sequential dependencies.

Consider first the effects of previous stimuli on the current response, the $\alpha_{i}$ in Table 1 . The vast majority (all but one) are negative, as in previous studies. In Table 1 , the values of $\alpha_{1}$ and $\alpha_{3}$ (odd subscripts) refer to previous stimuli with a frequency different from that of the current stimulus, while those of $\alpha_{2}$ and $\alpha_{4}$ (even subscripts) refer to previous stimuli with the same frequency as that of the current stimulus. For the frequency pairs inside each other's critical bands, the mean coefficients across frequencies are nearly equal (mean $\alpha_{1}=-0.049$; mean $\alpha_{2}$ $=-0.053$ ). For the outside pairs, the mean same frequency $\alpha_{2}$ is larger in absolute value than that for the inside pairs and about three times the (absolute) size of the mean different frequency $\alpha_{1}$, which is smaller in absolute value than that for the inside pairs (mean $\alpha_{1}=$ -0.025 ; mean $\alpha_{2}=-0.073$ ). This impression is confirmed by $t$ tests on differences between individual subject's values for $\alpha_{1}$ and $\alpha_{2}$ for each frequency individually and for all frequencies combined. For the inside frequencies, none of the individual tests was significant, nor was the grouped test $[t(7)=1.12, p=.30]$. For the outside frequencies, six of the eight individual tests were significant (see Table 1) and so was the grouped test $[t(7)$ $=3.39, p=.01]$. Another way to assess these effects is through an ANOVA, using the entries in Table 1 with repeated measures on the $\alpha_{1}$ versus $\alpha_{2}$ factor and between groups for the inside versus outside factor. In this analysis, neither of the main effects was significant, but the interaction was $[F(1,14)=8.49, p=.011]$. Bonferroni $t$ tests $(E W=0.05)$ of inside versus outside mean $\alpha_{1}$ $(-0.49$ vs. -0.28$)$ and $\alpha_{2}(-0.53$ vs. -.073$)$ were both significant. A similar pattern holds for $\alpha_{3}$ and $\alpha_{4}$. Clearly, the magnitude of contrastive stimulus dependencies depends on whether the frequencies of previous and present stimuli are inside or outside each other's critical bands. 
Table 1

Regression Coefficients from Equation 3

\begin{tabular}{|c|c|c|c|c|c|c|c|c|c|}
\hline Frequency & $\tau$ & $\beta_{1}$ & $\alpha_{1}$ & $\beta_{2}$ & $\alpha_{2}$ & $\beta_{3}$ & $\alpha_{3}$ & $\beta_{4}$ & $\alpha_{4}$ \\
\hline \multicolumn{10}{|c|}{ Inside CB } \\
\hline $\begin{array}{r}65 \\
100\end{array}$ & $\begin{array}{l}.677 \dagger \\
.541 \dagger\end{array}$ & $\begin{array}{l}.270 \dagger \\
.238 \dagger\end{array}$ & $\begin{array}{l}-.074^{*} \\
-.072^{*}\end{array}$ & $\begin{array}{l}.083 \dagger \\
.098 \dagger\end{array}$ & $\begin{array}{l}-.066 \dagger \\
-.071 \dagger\end{array}$ & $\begin{array}{l}.023 \\
.047\end{array}$ & $\begin{array}{l}-.019 \\
-.027^{*}\end{array}$ & $\begin{array}{l}.040 \\
.095\end{array}$ & $\begin{array}{l}-.018 \\
-.051 \dagger\end{array}$ \\
\hline $\begin{array}{l}200 \\
250\end{array}$ & $\begin{array}{l}.523 \dagger \\
.504 \dagger\end{array}$ & $\begin{array}{l}.203+ \\
.174 \dagger\end{array}$ & $\begin{array}{l}-.042 \\
-.026\end{array}$ & $\begin{array}{l}.095^{*} \\
.093^{*}\end{array}$ & $\begin{array}{l}-.054^{*} \\
-.035\end{array}$ & $\begin{array}{l}.058 \\
.031\end{array}$ & $\begin{array}{l}-.028 \\
-.032 *\end{array}$ & $\begin{array}{l}.010 \\
.064\end{array}$ & $\begin{array}{l}-.025 \\
-.050\end{array}$ \\
\hline $\begin{array}{l}1000 \\
1100\end{array}$ & $\begin{array}{l}.432 \dagger \\
.434 \dagger\end{array}$ & $\begin{array}{l}.239 \dagger \\
.228 \dagger\end{array}$ & $\begin{array}{l}-.039 \dagger \\
-.054 \dagger\end{array}$ & $\begin{array}{l}.090 \dagger \\
.078^{*}\end{array}$ & $\begin{array}{l}-.047 \dagger \\
-.039 \dagger\end{array}$ & $\begin{array}{l}.078 \\
.026\end{array}$ & $\begin{array}{l}-.048 \\
-.022\end{array}$ & $\begin{array}{r}-.006 \\
.040\end{array}$ & $\begin{array}{l}-.012 \\
-.028\end{array}$ \\
\hline $\begin{array}{r}9000 \\
10000\end{array}$ & $\begin{array}{l}.394 \dagger \\
.406 \dagger\end{array}$ & $\begin{array}{l}.275 \dagger \\
.332 \dagger\end{array}$ & $\begin{array}{l}-.025 \\
-.058 \dagger\end{array}$ & $\begin{array}{l}.126 \dagger \\
.151+\end{array}$ & $\begin{array}{l}-.042^{*} \\
-.072 *\end{array}$ & $\begin{array}{l}.024 \\
.016\end{array}$ & $\begin{array}{l}-.018 \\
-.022 *\end{array}$ & $\begin{array}{r}-.010 \\
.035\end{array}$ & $\begin{array}{l}-.002 \\
-.038\end{array}$ \\
\hline Mean & .489 & .245 & -.049 & .102 & -.053 & .038 & -.027 & .034 & -.028 \\
\hline \multicolumn{10}{|c|}{ Outside CB } \\
\hline $\begin{array}{r}100 \S \\
1000 \ddagger\end{array}$ & $\begin{array}{l}.602 \dagger \\
.453 t\end{array}$ & $\begin{array}{l}.100 \dagger \\
.154 \dagger\end{array}$ & $\begin{array}{l}-.011 \\
-.044^{*}\end{array}$ & $\begin{array}{l}.133 \dagger \\
.150 \dagger\end{array}$ & $\begin{array}{l}-.081 \dagger \\
-.094 *\end{array}$ & $\begin{array}{r}.035 \\
-.011\end{array}$ & $\begin{array}{l}-.020 \\
-.005\end{array}$ & $\begin{array}{l}.090 \dagger \\
.028\end{array}$ & $\begin{array}{l}-.066 \dagger \\
-.020\end{array}$ \\
\hline $\begin{array}{c}200 \\
10008\end{array}$ & $\begin{array}{l}.550 \dagger \\
.425 \dagger\end{array}$ & $\begin{array}{l}.197 \dagger \\
.139 \dagger\end{array}$ & $\begin{array}{l}-.039 \\
-.000\end{array}$ & $\begin{array}{l}.073^{*} \\
.112^{*}\end{array}$ & $\begin{array}{l}-.033^{*} \\
-.048^{*}\end{array}$ & $\begin{array}{l}.042 \\
.017\end{array}$ & $\begin{array}{l}-.026 \\
-.019\end{array}$ & $\begin{array}{l}.054^{*} \\
.057 \dagger\end{array}$ & $\begin{array}{l}-.041^{*} \\
-.036 \dagger\end{array}$ \\
\hline $\begin{array}{r}200 \S \\
9000 \S\end{array}$ & $\begin{array}{l}.616 \dagger \\
.513 \dagger\end{array}$ & $\begin{array}{l}.146 \dagger \\
.190 \dagger\end{array}$ & $\begin{array}{l}-.027^{*} \\
-.020 \dagger\end{array}$ & $\begin{array}{l}.163 \dagger \\
.170 \dagger\end{array}$ & $\begin{array}{l}-.126 \dagger \\
-.082 *\end{array}$ & $\begin{array}{l}.066^{*} \\
.050\end{array}$ & $\begin{array}{l}-.041+ \\
-.043^{*}\end{array}$ & $\begin{array}{l}.048 * \\
.092 \dagger\end{array}$ & $\begin{array}{l}-.051 \dagger \\
-.058 \dagger\end{array}$ \\
\hline $\begin{array}{l}1000 \ddagger \\
9000\end{array}$ & $\begin{array}{l}.393 \dagger \\
.419 \dagger\end{array}$ & $\begin{array}{l}.112^{*} \\
.365 \dagger\end{array}$ & $\begin{array}{l}-.011 \\
-.072 *\end{array}$ & $\begin{array}{l}.155 \dagger \\
.146 t\end{array}$ & $\begin{array}{l}-.057 \dagger \\
-.060 \dagger\end{array}$ & $\begin{array}{l}.046^{*} \\
.026\end{array}$ & $\begin{array}{r}.014 \\
-.007\end{array}$ & $\begin{array}{l}.062 * \\
.062 *\end{array}$ & $\begin{array}{l}-041^{*} \\
-.032\end{array}$ \\
\hline Mean & .496 & .175 & -.028 & .138 & -.073 & .034 & -.018 & .062 & -.043 \\
\hline
\end{tabular}

Table 2

$R^{2}$ Increases from Equation 3

\begin{tabular}{|c|c|c|c|c|c|c|c|c|c|}
\hline Frequency & $I_{n}$ & $R_{n-1}$ & $I_{n-1}$ & $R_{n-2}$ & $I_{n-2}$ & $R_{n-3}$ & $I_{n-3}$ & $R_{n-4}$ & $I_{n-4}$ \\
\hline \multicolumn{10}{|c|}{ Inside CB } \\
\hline $\begin{array}{r}65 \\
100\end{array}$ & $\begin{array}{l}.792 \\
.750\end{array}$ & $\begin{array}{l}.024 \\
.031\end{array}$ & $\begin{array}{l}.007 \\
.008\end{array}$ & $\begin{array}{l}.002 \\
.002\end{array}$ & $\begin{array}{l}.003 \\
.004\end{array}$ & $\begin{array}{l}.000 \\
.001\end{array}$ & $\begin{array}{l}.001 \\
.001\end{array}$ & $\begin{array}{l}.000 \\
.001\end{array}$ & $\begin{array}{l}.001 \\
.003\end{array}$ \\
\hline $\begin{array}{l}200 \\
250\end{array}$ & $\begin{array}{l}.796 \\
.775\end{array}$ & $\begin{array}{l}.020 \\
.021\end{array}$ & $\begin{array}{l}.006 \\
.006\end{array}$ & $\begin{array}{l}.002 \\
.002\end{array}$ & $\begin{array}{l}.003 \\
.003\end{array}$ & $\begin{array}{l}.001 \\
.001\end{array}$ & $\begin{array}{l}.002 \\
.001\end{array}$ & $\begin{array}{l}.002 \\
.001\end{array}$ & $\begin{array}{l}.001 \\
.003\end{array}$ \\
\hline $\begin{array}{l}1000 \\
1100\end{array}$ & $\begin{array}{l}.815 \\
.819\end{array}$ & $\begin{array}{l}.028 \\
.019\end{array}$ & $\begin{array}{l}.004 \\
.004\end{array}$ & $\begin{array}{l}.001 \\
.002\end{array}$ & $\begin{array}{l}.003 \\
.001\end{array}$ & $\begin{array}{l}.000 \\
.000\end{array}$ & $\begin{array}{l}.003 \\
.002\end{array}$ & $\begin{array}{l}.002 \\
.001\end{array}$ & $\begin{array}{l}.000 \\
.002\end{array}$ \\
\hline $\begin{array}{r}9000 \\
10000\end{array}$ & $\begin{array}{l}.719 \\
.689\end{array}$ & $\begin{array}{l}.063 \\
.055\end{array}$ & $\begin{array}{l}.007 \\
.011\end{array}$ & $\begin{array}{l}.002 \\
.002\end{array}$ & $\begin{array}{l}.004 \\
.007\end{array}$ & $\begin{array}{l}.001 \\
.003\end{array}$ & $\begin{array}{l}.002 \\
.001\end{array}$ & $\begin{array}{l}.001 \\
.001\end{array}$ & $\begin{array}{l}.001 \\
.003\end{array}$ \\
\hline Mean & .769 & .033 & .007 & .002 & .004 & .001 & .002 & .001 & .002 \\
\hline \multicolumn{10}{|c|}{ Outside CB } \\
\hline $\begin{array}{r}100 \\
1000\end{array}$ & $\begin{array}{l}.839 \\
.765\end{array}$ & $\begin{array}{l}.009 \\
.018\end{array}$ & $\begin{array}{l}.001 \\
.002\end{array}$ & $\begin{array}{l}.001 \\
.001\end{array}$ & $\begin{array}{l}.004 \\
.008\end{array}$ & $\begin{array}{l}.001 \\
.001\end{array}$ & $\begin{array}{l}.001 \\
.001\end{array}$ & $\begin{array}{l}.000 \\
.001\end{array}$ & $\begin{array}{l}.002 \\
.001\end{array}$ \\
\hline $\begin{array}{r}200 \\
1000\end{array}$ & $\begin{array}{l}.834 \\
.755\end{array}$ & $\begin{array}{l}.016 \\
.036\end{array}$ & $\begin{array}{l}.002 \\
.001\end{array}$ & $\begin{array}{l}.000 \\
.002\end{array}$ & $\begin{array}{l}.001 \\
.005\end{array}$ & $\begin{array}{l}.000 \\
.001\end{array}$ & $\begin{array}{l}.001 \\
.001\end{array}$ & $\begin{array}{l}.000 \\
.001\end{array}$ & $\begin{array}{l}.001 \\
.002\end{array}$ \\
\hline $\begin{array}{r}200 \\
9000\end{array}$ & $\begin{array}{l}.799 \\
.679\end{array}$ & $\begin{array}{l}.032 \\
.065\end{array}$ & $\begin{array}{l}.007 \\
.020\end{array}$ & $\begin{array}{l}.001 \\
.004\end{array}$ & $\begin{array}{l}.010 \\
.015\end{array}$ & $\begin{array}{l}.001 \\
.001\end{array}$ & $\begin{array}{l}.001 \\
.003\end{array}$ & $\begin{array}{l}.001 \\
.001\end{array}$ & $\begin{array}{l}.001 \\
.004\end{array}$ \\
\hline $\begin{array}{l}1000 \\
9000\end{array}$ & $\begin{array}{l}.785 \\
.689\end{array}$ & $\begin{array}{l}.017 \\
.050\end{array}$ & $\begin{array}{l}.004 \\
.014\end{array}$ & $\begin{array}{l}.004 \\
.002\end{array}$ & $\begin{array}{l}.004 \\
.008\end{array}$ & $\begin{array}{l}.002 \\
.001\end{array}$ & $\begin{array}{l}.000 \\
.002\end{array}$ & $\begin{array}{l}.002 \\
.001\end{array}$ & $\begin{array}{l}.001 \\
.004\end{array}$ \\
\hline Mean & .768 & .030 & .006 & .002 & .007 & .001 & .001 & .001 & .002 \\
\hline
\end{tabular}


The pattern of $R^{2}$ increases for previous stimuli $\left(I_{n-i}\right)$ displayed in Table 2 is consistent with the pattern of regression coefficients discussed above. All eight of the $R^{2}$ increases for $I_{n-1}$ are greater than those for $I_{n-2}$ for the inside frequencies, whereas this relation holds for only four of the outside frequencies. The mean $R^{2}$ increases for $I_{n-1}$ and $I_{n-2}$ for the inside condition were 0.007 and 0.004 , while for the outside condition they were 0.006 and 0.007 . Typically, stimuli at smaller lags have larger $R^{2}$ increases, as they do in the inside condition (see Ward, 1985). The inconsistency of this pattern for the outside condition reflects the lessened influence of previous stimuli of frequency outside the critical band of the current stimulus, even though they occur at a lag of 1 .

Consider now the effects of previous responses on the current response. These are summarized by the $\beta_{k}$ coefficients in Table 1 and the $R^{2}$ increases attributed to $R_{n-k}$ in Table 2. Again, coefficients with odd subscripts refer to trials on which the stimulus had a frequency different from that of the current stimulus, while those with even
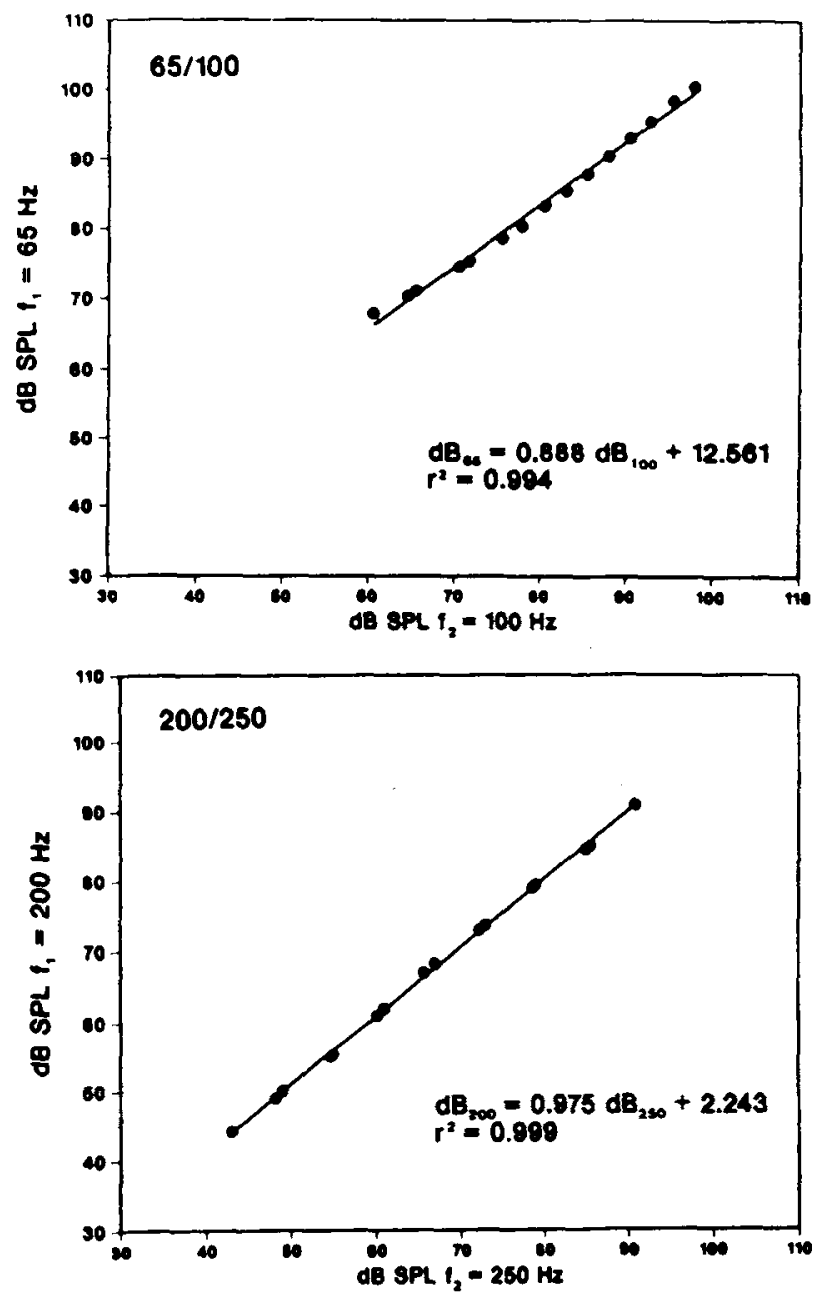

subscripts refer to trials on which the stimulus had the same frequency as that of the current stimulus. As is usual for these effects, $\beta$, is positive and large and significantly different from zero for all frequencies, as is $\beta_{2}$. For the inside frequency pairs, $\beta_{1}$ is greater than $\beta_{2}$ for each frequency, and the grouped $t$ test across frequencies is significant [mean $\beta_{1}=0.245$; mean $\beta_{2}=0.102 ; t(7)=$ $11.56, p<.001]$. For the outside frequency pairs, $\beta_{1}$ is greater than $\beta_{2}$ for five of the eight frequencies, and although the mean coefficients across frequencies are in the same direction as for the inside pairs (mean $\beta_{1}=$ 0.175 ; mean $\beta_{2}=0.138$ ), the grouped test is not significant $[t(7)=1.19, p=.27]$. An ANOVA of the $\beta_{1}$ and $\beta_{2}$ entries in Table 1 for the various frequencies reveals that the main effect of inside versus outside is not significant, but that the main effect for $\beta_{1}$ versus $\beta_{2}$ is $[F(1,14)$ $=28.163, p<.001]$, as is the interaction $[F(1,14)=$ $9.595, p=.008]$. Bonferroni $t$ tests $(E W=0.05)$ were significant for inside versus outside mean $\beta_{1}(0.245 \mathrm{vs}$. $0.175)$ but not for $\beta_{2}(0.102$ vs. 0.138$)$. Both analyses
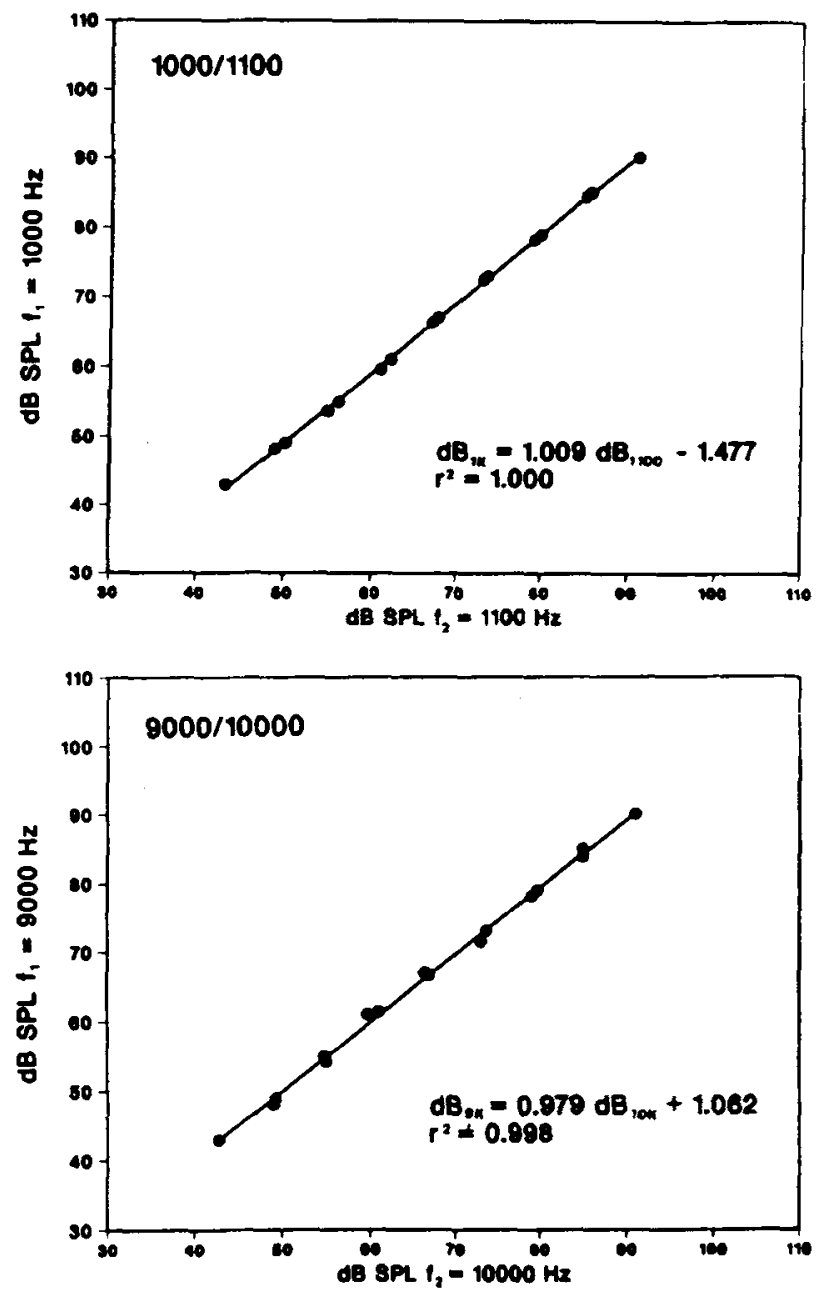

Figure 1. Average cross-frequency matching functions for the four frequency pairs inside critical band. Equations of the best fitting straight lines are also displayed. 
indicate a decrease in the size of the regression coefficients for previous responses if the frequency of their stimuli was outside the critical band of the current stimulus. To see whether this is indicative of an overall decrease in the magnitude of the dependency of the current response on responses to those stimuli, we must examine the $R^{2}$ increases. The mean $R^{2}$ increase attributed to $R_{n-1}$ was 0.033 and 0.030 in the inside and outside conditions, respectively, while the mean $R^{2}$ increase attributed to $R_{n-2}$ was 0.002 in both. Clearly, $R_{n-1}$ dominates the response dependencies in both conditions, implying that the changes in magnitudes of regression coefficients do not reflect lessened influence of previous responses to stimuli outside the critical band of the current stimulus, but only a change in the form of that influence. Taken together, these results indicate that the inside-outside manipulation had minimal effect on the magnitude of assimilative response dependencies-as would be expected, since these are supposed to arise from a source that would not be greatly
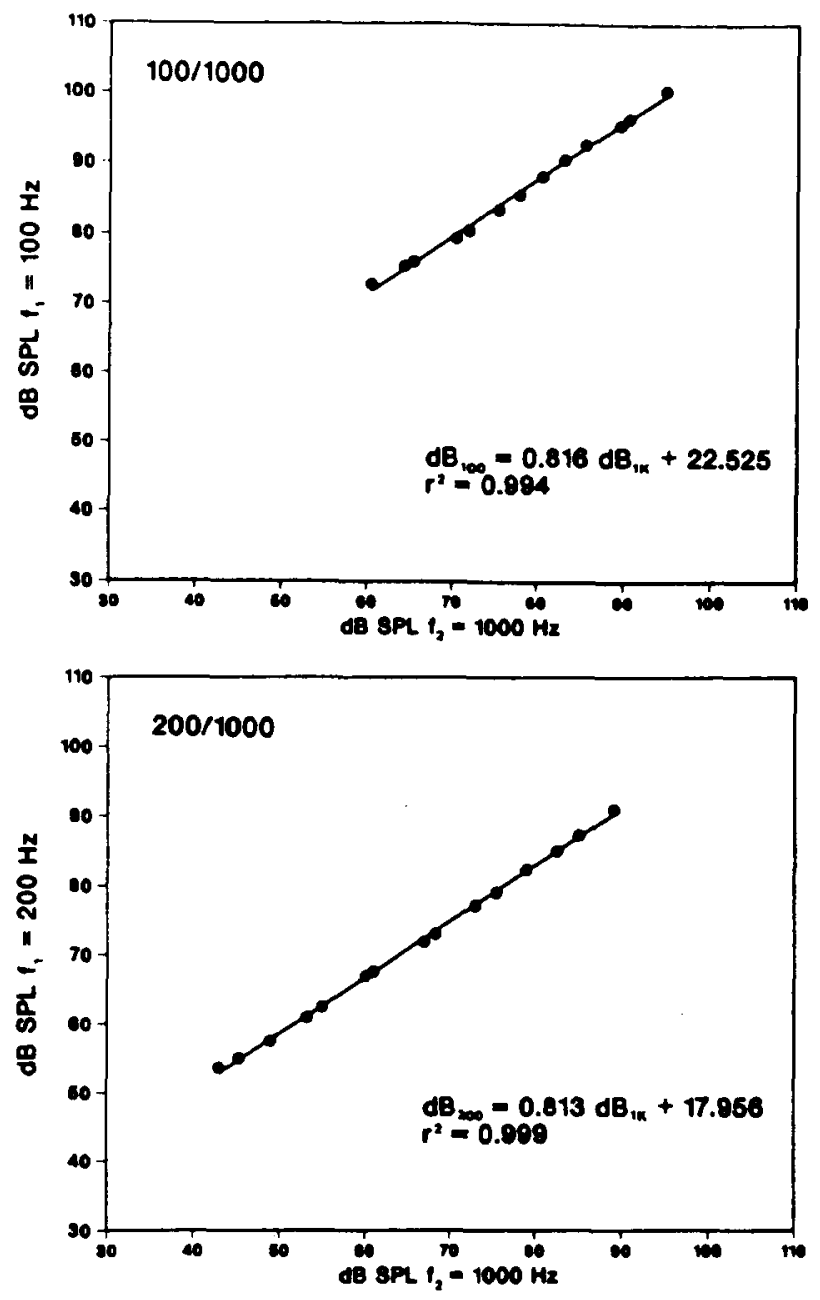

affected by variations in the interaction of internal sensory representations of stimulus intensities.

\section{Equal-Loudness Contours}

Figures 1 and 2 present the cross-frequency loudness matching functions obtained for each of the eight pairs of frequencies scaled. The functions shown are based on transformed geometric mean responses across all 8 subjects at each intensity for each frequency. All subjects' responses were transformed by multiplying each response by a number that resulted in the geometric mean response to the fifth most intense stimulus at the lower of each pair of frequencies judged in a particular run being equal to 100 (the designated modulus on each run). This transform was necessary, since different subjects had the modulus designated for different frequencies and thus used different numbers to indicate the same perceived loudness on different runs. These transformed geometric mean responses were then used in the manner of J. C. Stevens
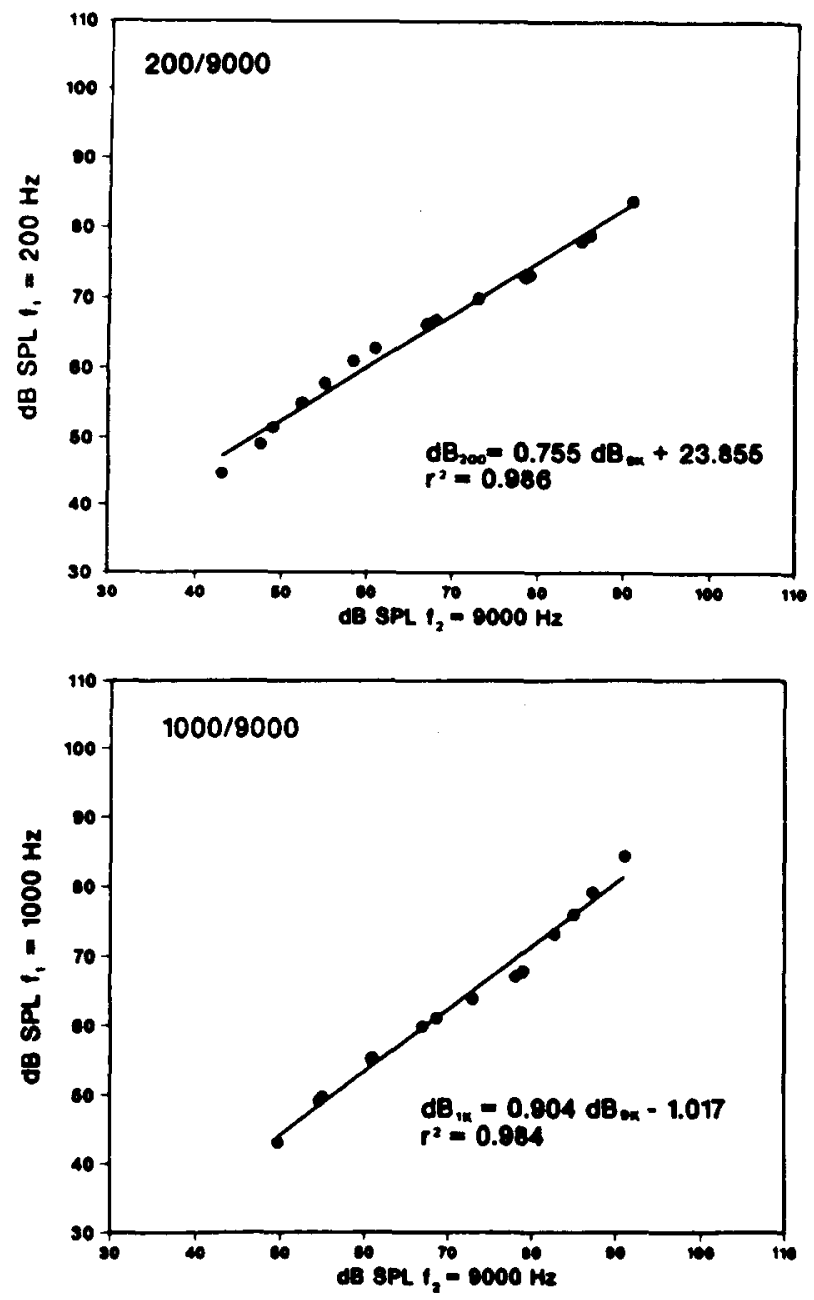

Figure 2. Average cross-frequency functions for the four frequency pairs outside critical band. Equations of the best fitting straight lines are also displayed. 
and Marks (1980, Appendix 2) to generate the matching functions. Essentially, adjacent pairs of stimulus intensities (in decibels) and log geometric mean responses were each averaged to produce a smoother function. Then, linear interpolation was used to determine for each of the (averaged adjacent) intensities on one frequency which intensity on the other frequency would have been given the same response. This procedure was then repeated for the "other" frequency with respect to the first. The resulting cross-frequency matching functions are highly linear in log-log plots, as is shown in Figures 1 and 2. Their slopes are significantly correlated with those predicted from the psychophysical functions based directly on subjects' responses (ratios of relevant $\tau$ s from Table $1 ; r=$ $0.763, p<.05$ ), although they differ somewhat because of the running averaging procedure used in generating the matching functions (mean difference $=-0.011$; mean absolute difference $=0.061$ ) .

Figure 3 displays the equal-loudness contours calculated from the cross-frequency loudness matching functions shown in Figure 1 and 2 . The 1000- $\mathrm{Hz}$ frequency was taken as the standard, as is common practice (but see Molino, 1973). The intensities of each of the other frequencies needed to match the canonical intensity at $1000 \mathrm{~Hz}$ were then calculated either directly from the matching function (equation of best fitting straight line shown in Figure 1 or Figure 2) for that frequency and $1000 \mathrm{~Hz}(100,200,1100$, and $9000 \mathrm{~Hz}$ ) or indirectly from the matching function of that frequency and another that was directly matched to $1000 \mathrm{~Hz}(65,250$, and $10000 \mathrm{~Hz})$.
The contours in Figure 2 are displayed for canonical intensities of the $1000-\mathrm{Hz}$ standard $(0,10,20, \ldots \mathrm{dB})$, including intensities far from those actually employed (e.g., near threshold). This is done purposely. The extrapolation downward in intensity is done to show that the cross-frequency matching functions can be successfully extrapolated into intensity ranges other than those in which they were obtained (e.g., can give contours similar to those of other studies; see next paragraph), including estimates of the absolute threshold contour $(0-\mathrm{dB}$ contour). Also, using the canonical intensities emphasizes that these contours are derived from the cross-frequency matching functions. This is both an advantage, since they may be more stable than direct matching functions, and a disadvantage, since they are indirect and do not reflect actual direct matches.

Three of the contours from Figure $3(0,40$, and $80 \mathrm{~dB}$, with the $1100-$ and $9000-\mathrm{Hz}$ points deleted) are replotted in Figure 4, along with contours from two previous studies. Only average $40-$ and $80-\mathrm{dB}$ contours (for 10 subjects) from Schneider et al. (1972) are shown, since they did not extrapolate contours below $40 \mathrm{~dB}$. The $1000-\mathrm{Hz}$ points on these contours were interpolated from their contours, and no frequencies higher than $1000 \mathrm{~Hz}$ are shown, since Schneider et al.'s (1972) highest frequency was $2500 \mathrm{~Hz}$ and the present study included no frequencies near that one. All three contours from Fletcher and Munson (1933) were read from a graph.

It is clear from Figure 4 that the equal-loudness contours generated from the present data, including the ex-

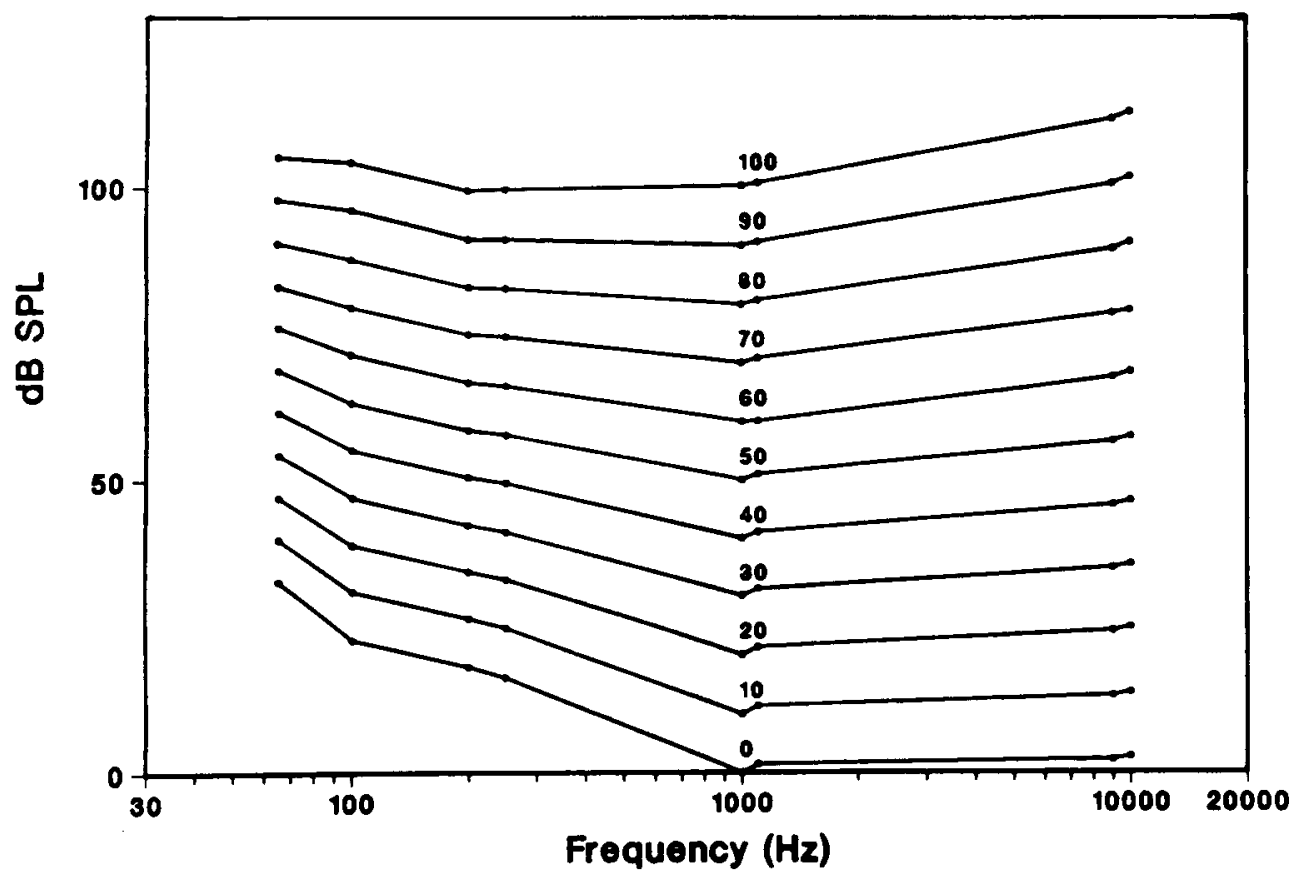

Figure 3. Equal-loudness contours calculated from the cross-frequency matching functions displayed in Figures 1 and 2 . Either the displayed equation or the regression equation obtained in the other direction was used to calculate intensities at various frequencies that "matched" the relevant canonical intensity at $1000 \mathrm{~Hz}$. 
trapolated ones at lower intensities, are similar to others generated with other methods (represented by the Fletcher and Munson [1933] contours). For example, the flattening of the contours at lower frequencies as intensity increases is clearly present. Also, greater intensities are needed to achieve equivalent loudnesses for frequencies both above and below the region of $1000 \mathrm{~Hz}$, as compared with frequencies in that region.

On the other hand, these contours do differ somewhat from others. The low-frequency ends of the contours are considerably flatter than those of Schneider et al. (1972), who, using a judgment method similar to that in the present study, found contours steeper than most others. In fact, Schneider et al.'s 40-dB contour crosses Fletcher and Munsons' (1933) 80-dB contour at $100 \mathrm{~Hz}$ and that of the present study at about $95 \mathrm{~Hz}$. Schneider et al. (1972) suggested that their $100-\mathrm{Hz}$ points were at least $12 \mathrm{~dB}$ too high because of leakage at the coupling between the ear and the phone. Subtracting $12 \mathrm{~dB}$ from the 100 $\mathrm{Hz}$ point on the Schneider et al. curves does bring them more into correspondence with some others (in particular those of Ross, 1967, who measured intensities at the eardrum and minimized low-frequency leakage), but it leaves them still steeper than the present curves. It is difficult to know what to make of these relationships between various equal-loudness contours. Certainly, as Kohfeld et al. (1981) and Ross (1967) suggested, some of the differences are attributable to differences in the way in which tone intensities were measured, whether at the coupler, in the ear canal, or in a free-field, and to the particular frequencies employed as standards. On the other hand, judgment method probably also plays a part, since in studies with similar methods and similar intensity measurement techniques (present study and Schneider et al., 1972), different contours have been obtained. Obviously, still more research is needed to obtain convergence between the various approaches to the determination of equal loudness across frequencies.

\section{Variation of Exponents with Frequency}

Table $1(\tau)$ and Figure 5 show the average power function exponents estimated from Equation 3 for the various frequencies used in this experiment. The corresponding $R^{2}$ increases associated with $I_{n}$ are displayed in Table 2 . The $R^{2}$ increases are uniformly large, although they vary somewhat with the pair of frequencies judged. There was no overall difference in $R^{2}$ increase between the inside and outside frequency pairs. However, although there is some variability, it is clear that the exponents estimated in this way do differ systematically with frequency, with lower frequencies showing larger exponents. An ANOVA of individual subjects' exponents across the 16 different frequency conditions showed that these differences are statistically reliable $[F(4.4,31)=4.32, p=$ $.006]$; since sphericity is violated in the data, Huynh-Feldt corrected degrees of freedom (shown above) were used to test significance (see Kirk, 1982).

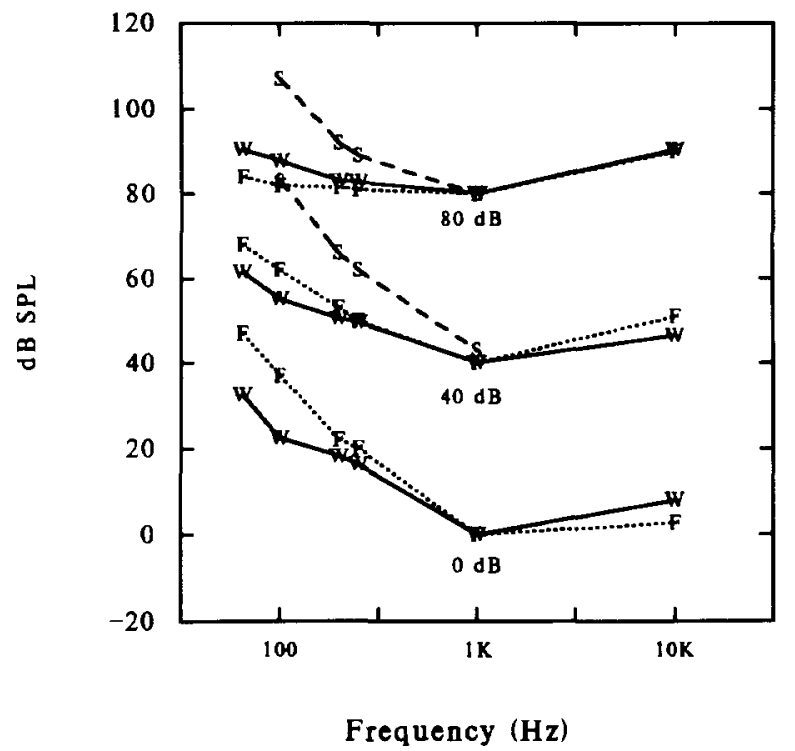

Figure 4. Three equal-loudness contours $(0,40$, and $80 \mathrm{~dB})$, replotted from Figure 3 (without 1100 - and $10000-H z$ points; "W"), along with roughly similar contours from two other studies: Fletcher and Munson (1933; "F") and Schneider et al. (1972; "S").

A separate ANOVA was done on only those data where exponents were available for both inside and outside critical band conditions $(100,200,1000$, and $9000 \mathrm{~Hz})$. For this analysis, estimates of the exponents from the two outside conditions for the $200-, 1000-$, and $9000-\mathrm{Hz}$ frequencies were averaged for each subject and treated together with the single estimates from the inside conditions and the single $100-\mathrm{Hz}$ outside estimate. This was thus a 2 (inside vs. outside) $\times 4$ (frequency) ANOVA. Again the sphericity test was significant, so Huynh-Feldt corrected degrees of freedom were used to test significance where relevant. The effect of frequency was again significant $[F(3,21)=9.53, p<.001]$, but the effects of inside versus outside the critical band $[F(1,7)=1.28, p=.296]$ and the interaction $[F(2.17,15.19)=0.48]$ were not.

Figure 5 also shows the predictions of Equation 2 concerning the way the exponents vary with frequency. This equation was based on both estimation of exponents from direct scaling results (e.g., Hellman \& Zwislocki, 1968; Schneider et al., 1972) and equal-loudness contours (S. S. Stevens, 1966; see Marks, 1974). Clearly, the present exponents are substantially smaller than those predicted by Equation 2, although the shape of the curve is similar. In fact, a modification of Equation 2, as below,

$$
\begin{aligned}
& f \leq 400: n=2[0.2+0.0004(400-f)] \\
& f>400: n=2[0.2],
\end{aligned}
$$

gives very accurate predictions of exponents in the present experiment (see Figure 5). Note that both the "canonical exponent" ( 0.33 in Equation 2$)$ and the multiplier of the quantity $(400-f)(0.0009$ in Equation 2$)$ have been 


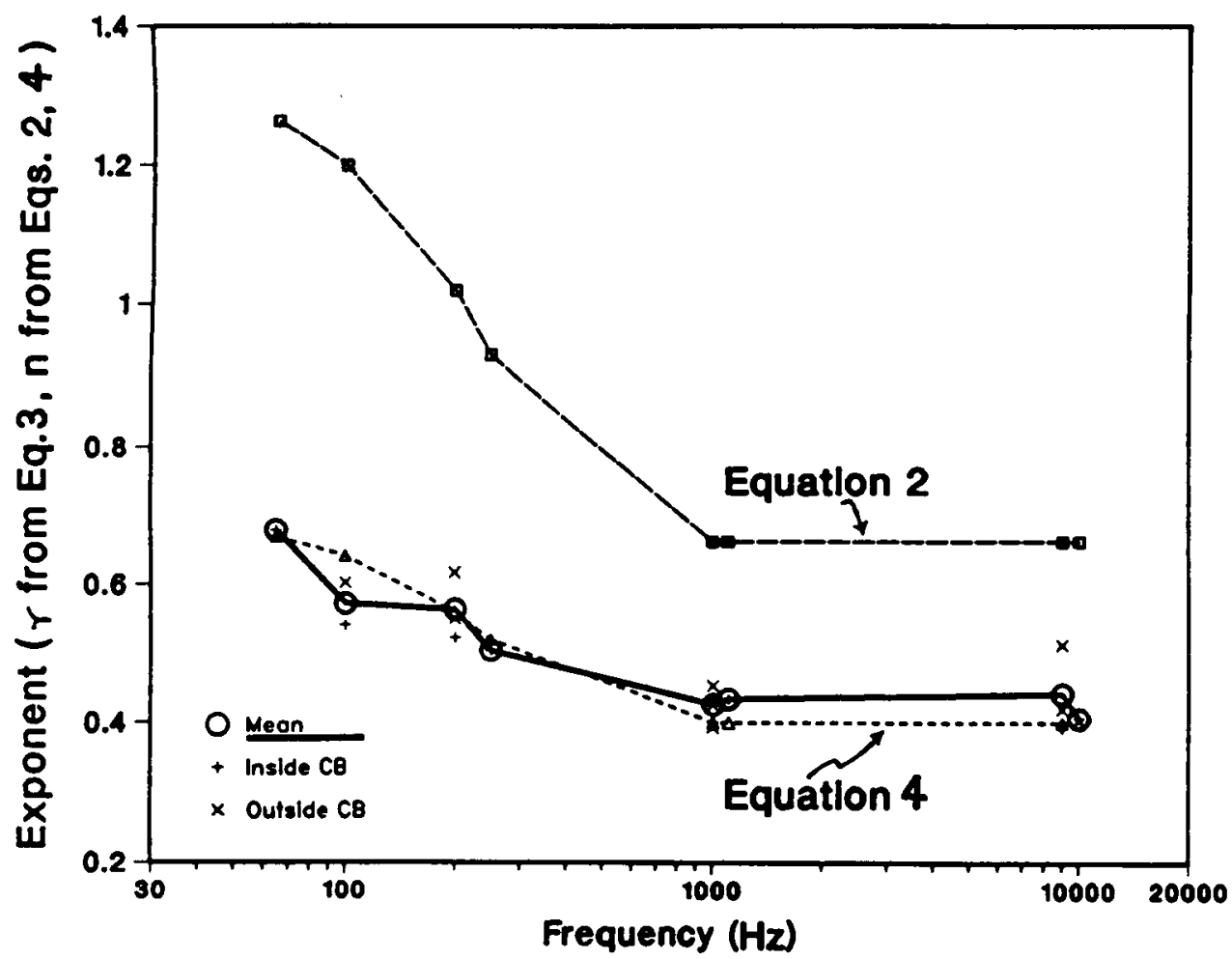

Figure 5. Exponents of power functions estimated from Equation 3 ( $\tau$ in Table 1), and means of these for each frequency (circles), as a function of frequency. Values calculated from Equations 2 (squares) and 4 (triangles) are also displayed.

decreased in Equation 4. In other words, in the present experiment, not only were the exponents in general smaller, but also the slope of the increase of exponents for frequencies less than $400 \mathrm{~Hz}$ was flatter. Exponents estimated in a different way from the data of Schneider et al. (1972) are very similar to the present ones, and also smaller than those predicted by Equation 2 .

Some insight into both why exponents vary with frequency and why different experiments may obtain substantially different equal-loudness contours (and different variation of exponent with frequency) can be obtained from consideration of Teghtsoonian's (1971) discussion of the relationship between stimulus range, response range, and exponents of power functions. He summarized the relationship that holds when a power function describes the psychophysical function in an equation similar to Equation 5 below:

$$
n=\log \left(R_{\max } / R_{\min }\right) / \log \left(S_{\max } / S_{\min }\right),
$$

where $R_{\max }$ is the average response given to $S_{\max }$, which is the most intense stimulus judged, and similarly for $\boldsymbol{R}_{\min }$ and $S_{\min }$. Thus, the exponent, $n$, is the ratio of the response range, $\log \left(R_{\max } / R_{\min }\right)$, to the stimulus range, $\log \left(S_{\max } / S_{\min }\right)$, with both ranges measured as intervals on a logarithmic scale (essentially rise over run for the typical log-log psychophysical function). Teghtsoonian (1971) argued that the variation of exponent with stimu- lus modality could be explained by the observation that subjects typically use a constant range of responses, regardless of modality, while the dynamic range of stimuli available to be judged varies dramatically with modality.

A similar argument applies here. The dynamic range of intensities available at frequencies lower than $400 \mathrm{~Hz}$ is smaller than that available at higher frequencies. Thus, if subjects used a constant response range for all frequencies, but experimenters presented a constant proportion of the dynamic range at each frequency, exponents of power functions describing the psychophysical functions would be larger below $400 \mathrm{~Hz}$, where thresholds rise sharply, and by an increasing amount the smaller the dynamic range. In fact, they should be predictable from the threshold curve as it varies with frequency, which defines the dynamic range for frequencies below $400 \mathrm{~Hz}$ since the threshold of feeling is roughly invariant in that region.

However, although response range may be more or less constant across some experimental conditions (e.g., variation of frequency or modality), others may affect it and, thus, the exponent, dramatically. Practice with a wide range of numbers on a continuum such as line length stabilizes responding (S. S. Stevens, 1975); feedback can produce specified responses, response ranges, and exponents (King \& Lockhead, 1981; Luce \& Green, 1978); and different judgment methods and/or contexts can affect the responses used (e.g., Marks, Szczesuil, \& Oh- 
lott, 1986; Ward, 1987). Furthermore, people vary in their experience with and sophistication of use of numbers, especially large ones, so that different samples of subjects may produce different results. Which subset of these factors affected exponents in the present experiment is unknown. The net effect was to depress exponent values in the present study (and in that of Schneider et al., 1972) relative to those predicted by Equation 2 .

\section{CONCLUSIONS}

The present data have confirmed the prediction that contrastive stimulus dependencies would be affected more strongly than would assimilative response dependencies by a manipulation that varied the amount of interaction of sensory representations of stimuli within the same modality. The manipulation involved creating pairs of frequencies of pure tones that were either inside each other's critical bands of frequency or not. Both regression coefficient and $R^{2}$ increase measures of contrastive stimulus dependencies were affected by whether previous and present stimuli were inside each other's critical band or not. $R^{2}$ increase measures of assimilative response dependencies were unaffected by the manipulation, and regression coefficients were generally larger for immediately previous responses even though they were made to stimuli with a different frequency than that of the current stimulus. This difference was somewhat smaller for the outside condition, indicating the possibility of factors that can influence the magnitude of the regression coefficients without correspondingly influencing the $R^{2}$ increases. Taken together, these results are consistent with the interpretation given by fuzzy judgment theory that most contrastive sequential dependencies arise from a sensory mechanism, whereas most assimilative ones arise from a different, possibly perceptual, mechanism.

Although magnitude estimations gave rise to reasonable equal-loudness contours from the present data, and consistent variation of exponents with frequency was also found, the relationships among various studies of both phenomena remains problematic. More work is needed to characterize the factors responsible for variation of equal-loudness contours across experiments, and to converge on a consistent relationship between power function exponents and frequency.

\section{REFERENCES}

CoRen, S., \& WARD, L. M. (1989). Sensation and perception (3rd ed.). San Diego, CA: Harcourt, Brace, Jovanovich.

FletCher, H. (1940). Auditory patterns. Reviews of Modern Physics, $12,47-65$.

Fletcher, H., \& MUNSON, W. A. (1933). Loudness, its definition, measurement, and calculation. Journal of the Acoustical Society of America, 5, 82-108.

Hawkins, J. E., JR., \& Stevens, S. S. (1950). The masking of pure tones and of speech by white noise. Joumal of the Acoustical Society of America, 22, 6-13.
Hellman, R. P., \& Zwislockı, J. J. (1968). Loudness determination at low sound frequencies. Journal of the Acoustical Society of America, $43,60-64$.

Jesteadt, W., Luce, R. D., \& Green, D. M. (1977). Sequential effects in judgments of loudness. Journal of Experimental Psychology: Human Perception \& Performance, 3, 92-104.

KING, M. C., \& LoCKHEAD, G. R. (1981). Response scales and sequential effects in judgment. Perception \& Psychophysics, 30, 599-603.

KingsaurY, B. A (1927). A direct comparison of the loudness of pure tones. Physical Review, 29, 588-600

KIRK, R. E. (1982). Experimental design: Procedures for the behavioral sciences (2nd ed.). Belmont, CA: Brooks/Cole.

Kohfeld, D. L., Santee, J. L., \& Wallace, N. D. (1981). Loudness and reaction time: I. Perception \& Psychophysics, 29, 535-549.

Levine, D. S., \& Grossberg, S. (1976). Visual illusions in neural networks: Line neutralization, tilt aftereffects, and angle expansions. Journal of Theoretical Biology, 61, 477-504.

Luce, R. D., Baird, J., Green, D. M., \& Smith, A. F. (1980). Two classes of models for magnitude estimation. Joumal of Mathematical Psychology, 22, 121-148.

LUCE, R. D., GREen, D. M. (1978). Two tests of a neural attention hypothesis for auditory psychophysics. Perception \& Psychophysics, 23, 363-371.

Marks, L. E. (1974). Sensory processes: The new psychophysics. New York: Academic Press

Marks, L. E., Szczesuil, R., \& Ohlott, P. (1986). On the crossmodal perception of intensity. Journal of Experimental Psychology: Human Perception \& Performance, 12, 517-534.

Molino, J. A. (1973). Pure-tone equal-loudness contours for standard tones of different frequencies. Perception \& Psychophysics, 14, 1-4.

Poulton, E. C., Edwards, R. S., \& Fowler, T. J. (1980). Eliminating subjective biases in judging the loudness of a $1-\mathrm{kHz}$ tone. Perception \& Psychophysics, 27, 93-103.

Robinson, D. W., \& DADSON, R. S. (1956). A re-determination of the equal-loudness relations for pure tones. British Joumal of Applied Physics, 7, 166-181.

Ross, S. (1967). Matching functions and equal-sensation contours for loudness. Journal of the Acoustical Society of America, 42, 778-793.

SCHARF, B. (1959). Loudness of complex sounds as a function of the number of components. Journal of the Acoustical Society of America, 31, 783-785.

SChNeider, B. A., \& BissetT, R. J. (1987). Equal loudness contours derived from comparisons of sensory differences. Canadian Journal of Psychology, 41, 429-441.

SChneider, B. A., Wright, A. A., Edelheit, W., Hock, P., HUMPHREY, C. (1972). Equal loudness contours derived from sensory magnitude judgments. Journal of the Acoustical Society of America, $\mathbf{5 1}$, 1951-1959.

Stevens, J. C., MARks, L. E. (1980). Cross-modality matching functions generated by magnitude estimation. Perception \& Psychophysics, 27, 379-389.

Stevens, S. S. (1956). The direct estimation of sensory magnitudesloudness. American Journal of Psychology, 69, 1-25.

STEVENS, S. S. (1966). Power group transformations under glare, masking, and recruitment. Joumal of the Acoustical Society of America, 39, 725-735.

Stevens, S. S. (1975). Psychophysics. New York: Wiley.

Teghtsoonian, R. (1971). On the exponents in Stevens' law and the constant in Ekman's law. Psychological Review, 78, 71-80.

WARD, L. M. (1979). Stimulus information and sequential dependencies in magnitude estimation and cross-modality matching. Journal of Experimental Psychology: Human Perception \& Performance, 5 , 444-459.

WARD, L. M. (1982). Mixed-modality psychophysical scaling: Sequential dependencies and other properties. Perception \& Psychophysics, 31, 53-62.

WARD, L. M. (1985). Mixed-modality psychophysical scaling: Interand intramodality sequential dependencies as a function of lag. Perception \& Psychophysics, 38, 512-522. 
WARD, L. M. (1986). Mixed-modality psychophysical scaling: Double cross-modality matching for "difficult" continua. Perception \& Psychophysics, 39, 407-417.

WARD, L. M. (1987). Remembrance of sounds past: Memory and psychophysical scaling. Journal of Experimental Psychology: Human Perception \& Performance, 13, 216-227.

ZADEH, L. (1965). Fuzzy sets. Information \& Control, 8, 338-353.

ZWICKer, E., FlottorP, G., \& STEVens, S. S. (1957). Critical band- width in loudness summation. Journal of the Acoustical Society of America, 29, 548-557.

ZWISLOCKI, J. J. (1965). Analysis of some auditory characteristics. In R. D. Luce, R. R. Bush, \& E. Galanter (Eds.), Handbook of mathematical psychology (pp. 1-97). New York: Wiley.

(Manuscript received June 26, 1989;

revision accepted for publication December 22, 1989.) 